\title{
PERCUTANEOUS PUNCTURE OF THE LEFT VENTRICLE
}

\author{
BY \\ EDWIN C. BROCKENBROUGH, ANDREW G. MORROW, JAMES TALBERT, \\ AND EUGENE BRAUNWALD
}

From the Clinic of Surgery, National Heart Institute, Bethesda, Maryland, U.S.A.

Received February 20, 1961

Left heart catheterization has become an increasingly important method for the pre-operative assessment of patients with congenital or acquired heart disease, and in recent years a variety of techniques have been introduced for gaining access to the left atrium and left ventricle (Morrow et al., 1960). When the usual clinical examinations indicate the need for such study the physician must select the method of left heart catheterization that will provide the information, in a particular patient, with a minimum of risk and discomfort. One of the techniques most commonly employed for access to the left ventricle is anterior percutaneous puncture. Although this method has been widely used since it was described and popularized by Brock and co-workers in 1956, relatively little information is available concerning experiences with this technique (Fleming et al., 1958; and Raynaud et al., 1959). At the National Heart Institute left ventricular puncture has been employed in the course of 226 hæmodynamic studies. The present report constitutes a description of the techniques and a summary of the experience with the procedure in this clinic.

\section{TECHNIQUE}

Left ventricular puncture is performed only in the operating room or cardiac catheterization laboratory. Systemic arterial pressure and the electrocardiogram are continuously monitored throughout the study. Equipment for internal and external cardiac defibrillation is immediately available and a surgeon experienced in the techniques of resuscitation is present. Adult patients are given pentobarbital $100 \mathrm{mg}$., orally, one hour before the procedure. Children usually receive a combination of meperidine, phenergan, and promazine, which is supplemented during the catheterization, if necessary, with light general anesthesia.

With the patient in the supine position the proposed site of puncture is selected. In most patients the apical approach is preferred. The skin and chest wall over the apical impulse are liberally infiltrated with a local anæsthetic agent down to the pleura. A 20 gauge needle, $10 \mathrm{~cm}$. in length, is attached to the three-way stopcock on the end of a Statham P23D pressure transducer. The side arm of the stopcock permits the injection of saline and indicator solutions during the procedure. The baseline or zero point for the pressure recording is determined with the needle and gauge held in the position in which the puncture will be made. As the electrocardiogram and the pressure at the needle tip are continuously observed on a cathode-ray oscilloscope, the needle is advanced through the chest wall and directed toward the second right intercostal space in a 


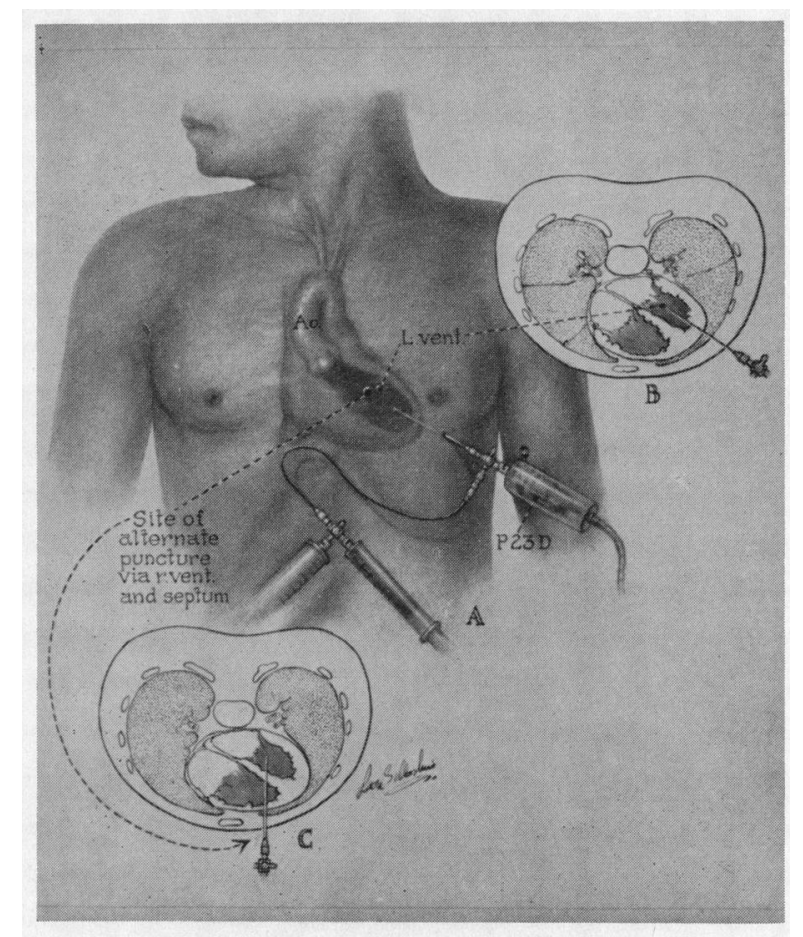

FIG. 1.-Technique and anatomical landmarks used in percutaneous left ventricular puncture. Both the apical (A and B), subxyphoid and parasternal (C) routes are illustrated. (Reproduced with permission from A.M.A. Archives of Internal Medicine.)

posteromedial direction so that the needle enters the cavity of the left ventricle in its long axis (Fig. 1, $A$ and B). The initial phasic pressure observed is often an intramyocardial one and may be distinguished from the true left ventricular pressure by its contour (Fig. 2). With further insertion the needle will usually enter the cavity of the ventricle. If, however, the puncture is unsuccessful the needle is withdrawn and redirected, usually more posteriorly. After satisfactory pressure tracings have been recorded, indicator dye or radioisotopes may be injected for the determination of cardiac output or the detection and localization of circulatory shunts (Long et al., 1960 and Cornell et al., 1961).

The parasternal and subxyphoid routes (Fig. 1, C) are alternative approaches to the left ventricle. With each of these methods the needle is directed so that it traverses the right ventricle and interventricular septum before entering the cavity of the left ventricle. Care must be taken to distinguish right and left ventricular pressures, particularly in patients with right ventricular hypertension.

After the procedure has been completed the patient's arterial pressure and electrocardiogram are observed for approximately twenty minutes before he leaves the catheterization laboratory. Upon his return to the ward the pulse and blood pressure are observed for several hours and a chest roentgenogram is obtained within the first hour.

\section{RESULTS}

Percutaneous puncture of the left ventricle was performed on 226 occasions in a total of 202 patients ranging in age from six weeks to 62 years. Thirty of the patients had acquired aortic valve disease, 66 acquired mitral valve disease, 31 combined acquired valve lesions, 49 congenital aortic 
A

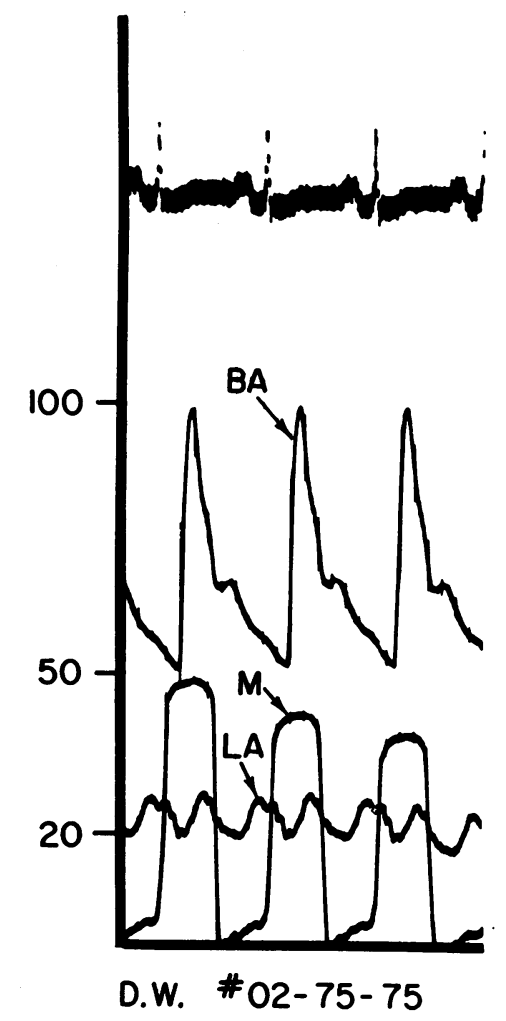

B

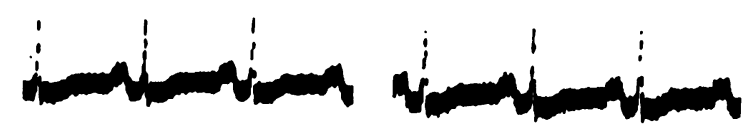

$1-1$ sec.-1
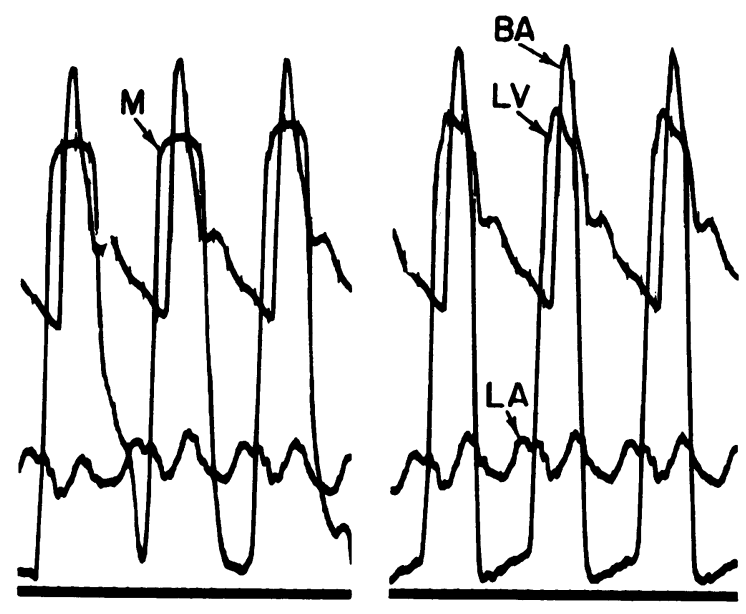

$4 / 26 / 60^{\prime}$

FIG. 2.-Recordings of brachial arterial (BA) left atrial (LA) and left ventricular (LV) pressures obtained in the course of percutaneous left ventricular puncture and transseptal left atrial puncture. The tracings marked $\mathbf{M}$ in segments $\mathbf{A}$ and $\mathbf{B}$ are representative of those obtained when the needle tip does not lie freely in the left ventricular cavity.

stenosis, and 26 had various forms of congenital heart disease other than aortic stenosis. The procedures were carried out by various staff members between 1957 and 1960 . The data obtained during these studies were reviewed and the procedures were classified as to whether or not satisfactory left ventricular pressure tracings were obtained. The procedure was successful in 210 instances $(93 \%)$. There was no mortality in the series but significant complications developed in 14 studies $(6 \%)$ (Table I). These complications included pneumothorax, cardiac tamponade, and unexplained hypotension. Premature ventricular contractions usually occurred at the time of puncture and other transient arrhythmias were occasionally noted but none required specific treatment. Sustained ventricular tachycardia or ventricular fibrillation were never encountered. Pneumothorax occurred in 11 patients and was of sufficient magnitude in six of them to warrant aspiration or closed drainage.

One patient with hypertrophic subaortic stenosis had multiple unsuccessful apical and parasternal punctures. About 30 minutes after the procedure he developed severe hypotension and the size of the cardiac silhouette was found by X-ray to be increased. Following pericardiocentesis in which 250 c.c. of blood were aspirated, the blood pressure returned to normal and no further treatment was necessary. Two patients became hypotensive after the procedure without signs of cardiac tamponade, and required vasopressors for a short period of time. It is of interest that seven of the complications $(50 \%)$ occurred among the 16 patients in whom the procedure was unsuccessful. Multiple punctures were performed in each of these seven patients. 
TABLE I

Significant Complications after Left Ventricular Puncture

\begin{tabular}{|c|c|c|c|c|c|}
\hline Patient & $\begin{array}{l}\text { Age } \\
\text { (y.) }\end{array}$ & Diagnosis & Entry into left ventricle & Complications & Treatment \\
\hline C. W. & 33 & Cong. A.S., preop. & Satisfactory & Pneumothorax $<15 \%$ & None \\
\hline R. B. & 15 & Cong. A.S., preop. & $\begin{array}{l}\text { Unsuccessful, multiple } \\
\text { punctures }\end{array}$ & Pneumothorax $<15 \%$ & None \\
\hline M. B. & 62 & Acq. A.S., A.R., preop. & $\begin{array}{l}\text { Successful, but required } \\
\text { several punctures }\end{array}$ & $\begin{array}{l}\text { Pneumothorax, } \\
\text { complete }\end{array}$ & $\begin{array}{l}\text { Closed } \\
\text { drainage }\end{array}$ \\
\hline M. S. & 17 & $\begin{array}{l}\text { Subaortic stenosis, } \\
\text { postop. }\end{array}$ & Satisfactory & Pneumothorax $<15 \%$ & None \\
\hline H. S. & 35 & Cong. A.S., postop. & Satisfactory & Pneumothorax $25 \%$ & Aspiration \\
\hline W. M. & 42 & Acq. A.S., preop. & Satisfactory & $\begin{array}{l}\text { Pneumothorax, } \\
\text { complete }\end{array}$ & Aspiration \\
\hline J. P. & 11 & Cong. A.S., preop. & Satisfactory & Pneumothorax $<15 \%$ & None \\
\hline G. $\mathbf{H}$. & 10 & Cong. A.S., preop. & $\begin{array}{l}\text { Successful, but required } \\
\text { several punctures }\end{array}$ & Pneumothorax $15 \%$ & $\begin{array}{c}\text { Closed } \\
\text { drainage }\end{array}$ \\
\hline R. M. & 53 & Acq. A.S., preop. & $\begin{array}{l}\text { Unsuccessful, multiple } \\
\text { punctures }\end{array}$ & Pneumothorax $15 \%$ & Aspiration \\
\hline P. P. & 42 & M.S., preop. & Satisfactory & Pneumothorax $<15 \%$ & None \\
\hline C. $\mathrm{H}$. & 44 & $\begin{array}{l}\text { M.S., M.R., A.S., A.R., } \\
\text { preop. }\end{array}$ & $\begin{array}{l}\text { Unsuccessful, multiple } \\
\text { punctures }\end{array}$ & Pneumothorax $25 \%$ & $\begin{array}{c}\text { Closed } \\
\text { drainage }\end{array}$ \\
\hline C. G. & 22 & $\begin{array}{l}\text { Hypertrophic subaortic } \\
\text { stenosis, preop. }\end{array}$ & $\begin{array}{l}\text { Unsuccessful multiple } \\
\text { parasternal punctures }\end{array}$ & Cardiac tamponade & Aspiration \\
\hline W. P. & 40 & M.S., preop. & $\begin{array}{l}\text { Unsuccessful-several } \\
\text { punctures }\end{array}$ & $\begin{array}{l}\text { Transient hypotension, } \\
\text { minimal } \\
\text { pneumothorax }\end{array}$ & Vasopressor \\
\hline D. W. & 53 & A.S., postop. & Unsuccessful & Transient hypotension & Vasopressor \\
\hline
\end{tabular}

A.S. $=$ aortic stenosis. $\quad$ A.R. $=$ aortic regurgitation. $\quad$ M.S. $=$ mitral stenosis. $\quad$ M.R. $=$ mitral regurgitation.

\section{COMMENT}

Six basic methods of left heart catheterization have been developed in recent years. These include the posterior percutaneous, transbronchial, retrosternal, and transseptal approaches for left atrial puncture and the retrograde arterial and anterior percutaneous approaches to the left ventricle. Of the four techniques for entering the left atrium, modifications of all but the retrosternal method also permit a catheter to be introduced across the mitral valve into the left ventricle. This means of obtaining left ventricular pressure is not always successful, particularly if there is significant mitral regurgitation. Since knowledge of the left ventricular pressure is required to determine pressure gradients across the mitral and aortic valves, a direct method of access to the ventricle is often necessary.

Of the two methods for direct determination of left ventricular pressure, the retrograde approach across the aortic valve was the first to be used. (Zimmerman et al., 1950). This method has been improved by Seldinger's modification (1953) which permits a catheter to be introduced into the brachial or femoral artery percutaneously without surgical exposure of the vessel. Although normal and incompetent aortic valves may usually be traversed with ease with this technique, in 
our experience it is difficult and frequently impossible to enter the left ventricle across a stenotic aortic valve.

The other means of obtaining left ventricular pressure without left atrial catheterization is direct puncture of the ventricle through the chest wall as described above. It has the advantages of requiring little time, of being relatively easy to perform, and of causing little discomfort to the patient. Furthermore, when used with one of the methods of left atrial puncture, it permits the recordings of simultaneous atrial and ventricular pressure tracings and the precise measurement of a diastolic pressure gradient across the mitral valve (Fig. 2, C).

In assessing the severity of aortic stenosis, left ventricular puncture is performed in conjunction with a measurement of the brachial artery or central aortic pressure. The size of the stenotic orifice may then be estimated using the Gorlin formula, from the systolic pressure gradient between the left ventricle and the aorta, and the left ventricular output as determined by the indicator dilution technique. A simple measurement of left ventricular pressure does not localize the site of outflow obstruction, information which is often necessary in the assessment of congenital lesions. While it is possible to catheterize the aorta through a 16 gauge needle introduced into the ventricle, the use of a needle of this size increases the hazard of the puncture. Fleming et al. (1958) reported two deaths from cardiac tamponade in a series of 59 patients in whom a 16 gauge needle was employed.

Left ventricular puncture may also be used for the injection of radioisotopes or for contrast radiography. The injection of a saline solution of $\mathrm{Kr}^{85}$ into the left ventricle while the radioactivity of the expired air is monitored, for example, will sometimes demonstrate the presence of small ventricular septal defects that cannot be detected by other means. Left ventricular angiocardiography may also be performed through a percutaneous needle (Lehman et al., 1957). While the retrograde and transseptal techniques (Brockenbrough and Braunwald, 1960) for the rapid injection of contrast media are preferred in this clinic, these approaches are sometimes not feasible, particularly in infants or small children. In such circumstances percutaneous ventricular puncture is a valuable alternative method.

Significant complications occurred after 6 per cent of the 226 left ventricular punctures, but the majority of these were not serious. While this is not a high incidence it is greater, in our experience, than that associated with either the transbronchial or transseptal techniques of left heart catheterization. Accordingly, in pre-operative patients we prefer to employ the transseptal approach; percutaneous puncture of the ventricle is used only if the ventricle cannot be entered with a catheter passed from the left atrium. Complications are less common in after operation patients in whom the pleural and pericardial spaces are obliterated. Percutaneous left ventricular puncture, therefore, lends itself well to the study of patients who have been operated upon for aortic valvular disease and in whom knowledge of the left atrial pressure is not essential.

In all patients the number of complications will be minimized if a needle of no greater calibre than 20 gauge is used and if attention is paid to the anatomical landmarks so that multiple punctures of the myocardium may be avoided whenever possible. If entry into the left ventricle is unsuccessful after several punctures the increased risk of continuing the procedure must be considered. The consequence of pneumothorax, hypotension, or tamponade will be substantially reduced if these possible hazards are recognized, if the patient is carefully observed following the study, and if prompt treatment is instituted should signs of one of them appear.

\section{SUMMARY}

Percutaneous puncture of the left ventricle was performed in the course of 226 hæmodynamic studies in 202 patients with congenital or acquired heart disease. No deaths occurred but significant complications were observed after 14 of the procedures. The technique of left ventricular puncture is described and the relative advantages and disadvantages of this method of left heart catheterization are discussed. 


\section{REFERENCES}

Brock, R., Milstein, B. B., and Ross, D. N. (1956). Thorax, 11, 163.

Brockenbrough, E. C., and Braunwald, E. (1960). Amer. J. Cardiol., 6, 1062.

Cornell, W. P., Braunwald, E., and Brockenbrough, E. C. (In press). Circulation Res.

Fleming, H. A., Hancock, E. W., Milstein, B. B., and Ross, D. N. (1958). Thorax, 13, 97.

Lehman, J. S., Musser, B. G., and Lykens, H. D. (1957). Amer. J. Roentgenol., 77, 207.

Long, R. T. L., Braunwald, E., and Morrow, A. G. (1960). Circulation, 21, 1126.

Morrow, A. G., Braunwald, E., and Ross, J., Jr. (1960). Arch. intern. Med., 105, 645.

Raynaud, R., Brochier, M., and Marand, P. (1959). Arch. Mal. Ceur., 12, 1374.

Seldinger, S. I. (1953). Acta radiol., 39, 368.

Zimmerman, H. A., Scott, R. W., and Becker, N. O. (1950). Circulation, 1, 357. 